\title{
LA RADIOACTIVITÉ ARTIFICIELLE : AUTOUR D'UNE DÉCOUVERTE
}

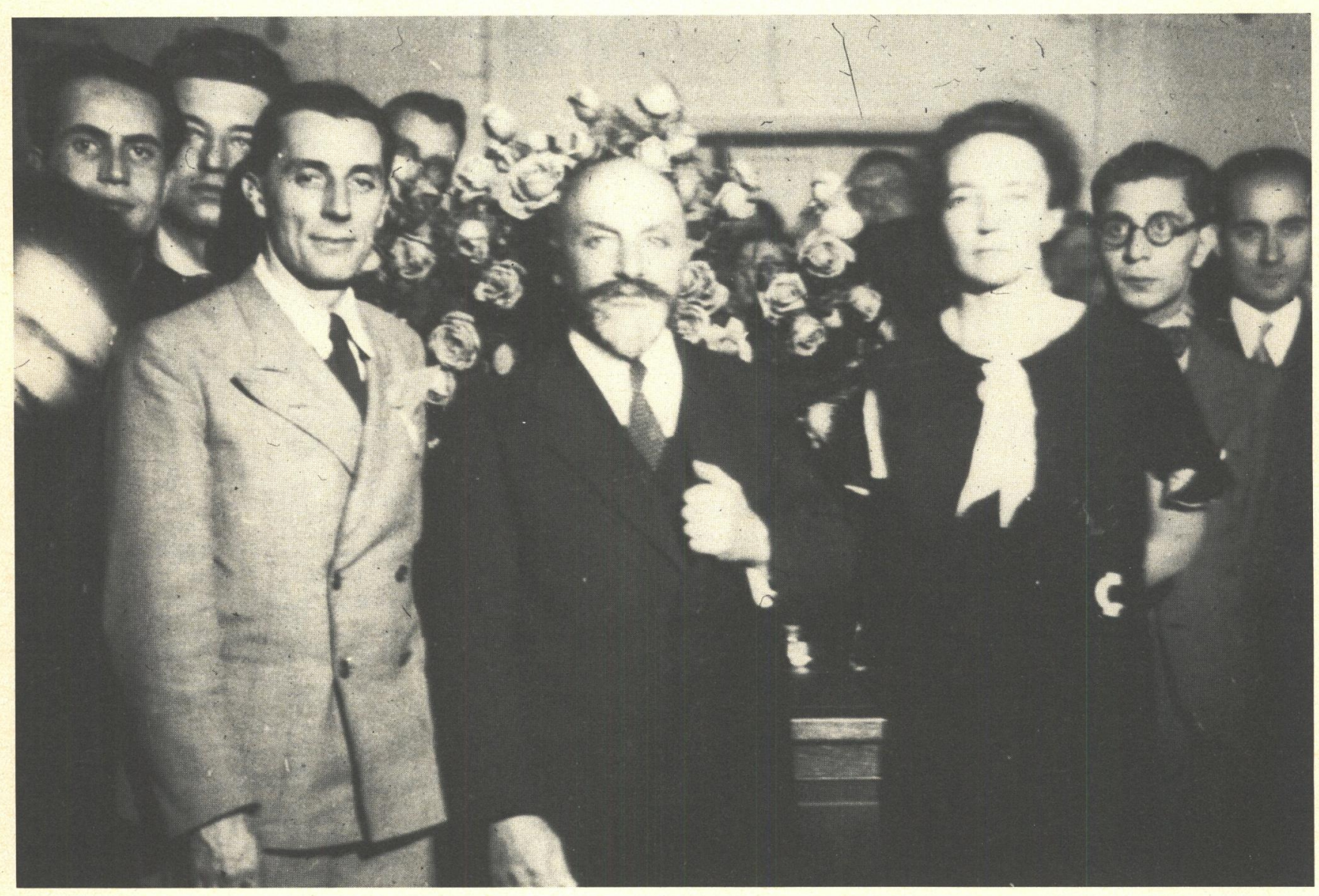

1935 : Célébration du Prix Nobel de Chimie attribué à Irène et Frédéric Joliot-Curie pour la découverte de la radioactivité artificielle.

$\mathbf{L}$ e cinquantenaire de la découverte de la radioactivité artificielle a été marqué en France par de très nombreuses manifestations - dont nous avons signalé les principales dans notre précédent numéro.

Ces manifestations ont été l'occasion, pour les personnalités qui les ont animées, d'une réflexion approfondie sur les travaux conduits par Irène et Frédéric Joliot-Curie et qui leur valurent le Prix Nobel de Chimie en 1935.

Outre l'expérience proprement dite effectuée par les deux savants français et les conditions concrètes de sa réalisation, le contexte scientifique général de cette découverte, sa portée fondamentale ainsi que les retombées pratiques considérables qu'elle allait entraîner ont été largement présentées et analysées.

C'est cette approche d'ensemble que restituent les textes qu'on va lire, la conclusion étant apportée par l'exposé que Laurent Fabius, ministre français de l'Industrie et de la Recherche a prononcé le 3 avril dernier à la Sorbonne, lors de la séance solennelle commémorant la découverte réalisée voici cinquante ans par Irène et Frédéric Joliot-Curie. 